\title{
Synthesis and Characterization of Hierarchical Porous $\alpha$-FeOOH for the Adsorption and Photodegradation of Rhodamine B
}

\author{
Jianliang Cao, ${ }^{1}$ Gaojie Li, ${ }^{1}$ Yan Wang, ${ }^{2}$ Guang Sun, ${ }^{1}$ Hari Bala, \\ Xiaodong Wang, ${ }^{1}$ and Zhanying Zhang ${ }^{1}$ \\ ${ }^{1}$ Cultivating Base for Key Laboratory of Environment-Friendly Inorganic Materials in University of Henan Province, \\ School of Materials Science and Engineering, Henan Polytechnic University, Jiaozuo, Henan 454000, China \\ ${ }^{2}$ School of Safety Science and Engineering, Henan Polytechnic University, Jiaozuo, Henan 454000, China \\ Correspondence should be addressed to Jianliang Cao; caojianliang@gmail.com and Yan Wang; yanwang@hpu.edu.cn
}

Received 27 December 2013; Accepted 10 January 2014; Published 18 February 2014

Academic Editor: Tian-Yi Ma

Copyright (C) 2014 Jianliang Cao et al. This is an open access article distributed under the Creative Commons Attribution License, which permits unrestricted use, distribution, and reproduction in any medium, provided the original work is properly cited.

\begin{abstract}
Hierarchical porous $\alpha$-FeOOH nanoparticles were controlled and prepared via a facile polystyrene (PS) microspheres-templated method. The $\alpha-\mathrm{Fe}_{2} \mathrm{O}_{3}$ was obtained by the calcination of the as-prepared $\alpha$-FeOOH. The resulting nanoparticles were characterized by X-ray diffraction analysis (XRD), scanning electron microscopy (SEM), transmission electron microscopy (TEM), and $\mathrm{N}_{2}$ sorption techniques. The adsorption and photodegradation of Rhodamine B performance were evaluated under UV light at room temperature. The results indicated that the photocatalytic activity of the $\alpha$-FeOOH nanoparticles is superior to $\alpha$ - $\mathrm{Fe}_{2} \mathrm{O}_{3}-200$ and $\alpha$ - $\mathrm{Fe}_{2} \mathrm{O}_{3}-300$ due to the hierarchically multiporous structure and high surface area. This convenient and low-cost process provides a rational synthesis alternative for the preparation of multiporous materials and the as-synthesis products have great foreground applications in many aspects.
\end{abstract}

\section{Introduction}

Textile dyeing is a significant consumer of water and producer of contaminated aqueous waste streams because textile dyeing processes are generally conducted in water-based dyeing baths and the dyeing processes require the addition of colorants and inorganic salts as dyeing promoter or retardant [1]. In a typical dyeing factory, about $0.2-0.5 \mathrm{~m}^{3}$ of water is needed to produce $1 \mathrm{~kg}$ of finished textiles [2]. Moreover, it is well known that some dye wastewater and its products such as aromatic amines are highly carcinogenic $[3,4]$. So dye wastewater has become a major problem in the environmental pollution control field $[5,6]$. Rhodamine $\mathrm{B}(\mathrm{RB})$ is widely used as a colorant in textiles and food stuffs and is also a well-known water tracer fluorescent [7]. It is harmful to human beings and animals and causes irritation of the skin, eyes, and respiratory tract. The carcinogenicity, reproductive and developmental toxicity, neurotoxicity, and chronic toxicity toward humans and animals have been experimentally proven [8]. The effluents containing dyes and pigments have been paid great attention in recent years since they can cause serious environmental problems. Water pollution containing hazardous mixtures which come from organic and inorganic pollutants had adverse effects on the environment, aquatic life, and human health. Besides this, the demand for an efficient and environmental friendly colour removal technology is also getting more attention the world over. Therefore, it is necessary to employ appropriate catalysts to degrade dyes in aqueous solution.

The removal methods of dyes have been considered in recent studies in the literature. These include physical adsorption, chemical degradation, biological degradation, photodegradation, or the synergic treatments of different methods [9-13]. Recently, much attention has been paid to photocatalytic methods for dye containing sewage decoloration using nanodispersed catalysts $\mathrm{TiO}_{2}$ [14], $\mathrm{Fe}_{2} \mathrm{O}_{3}$ [15], $\mathrm{ZnO}[16,17], \mathrm{SnO}_{2}$ [18], and so forth. These methods use light energy to initiate chemical reactions in the presence of 
photocatalysts that are mostly semiconductor materials. Heterogeneous photocatalysis using a semiconductor is a new, effective, and rapid technique for the removal of pollutants from water [19]. Among those nanomaterials, metal oxides represent one of the most diverse classes of materials with both fundamental and technological importance. One of the metal oxides which occur ubiquitously in the environment is iron oxides [20, 21]. Especially, compared to other potential photocatalysts, goethite $(\alpha-\mathrm{FeOOH})$ and hematite $\left(\alpha-\mathrm{Fe}_{2} \mathrm{O}_{3}\right)$ are extremely common in soils and sediments at and near the Earth's surface [22].

So far, in order to explore its novel properties and expand its applications, many efforts have been devoted to the synthesis of $\alpha-\mathrm{Fe}_{2} \mathrm{O}_{3}$ with different morphologies, including nanoparticles, nanowires, nanobelts, nanorods, and nanotubes [23-27]. It has been demonstrated that the semiconductor-based photocatalytic materials with hollow structures have higher photocatalytic activity due to the special hierarchical morphology and higher specific surface area [28]. Both $\alpha$-FeOOH and $\alpha-\mathrm{Fe}_{2} \mathrm{O}_{3}$ nanocrystallites exhibit unique reactivity at the nanoscale. In the catalytic oxidation of aqueous $\mathrm{Mn}^{2+}$, the rate exhibited by $7 \mathrm{~nm} \alpha$ $\mathrm{Fe}_{2} \mathrm{O}_{3}$ nanocrystals is 1 to 2 orders of magnitude faster than that of $37 \mathrm{~nm} \alpha-\mathrm{Fe}_{2} \mathrm{O}_{3}$ nanocrystals [29]. Zeng et al. [30] studied degradation of RB solution on iron dioxided with various structures under UV light and found that the catalytic performance of the three $\alpha-\mathrm{Fe}_{2} \mathrm{O}_{3}$ samples possesses the sequence of nanoflowers $>$ nanorods $>$ naoparticles, which agrees with the sequence that the surface areas of the samples decreased. To date, systematic studies of the impact of particle size and shape on photocatalytic property by iron oxides are still lacking. Over the past decade, template-based processes demonstrate high efficiency for the construction of porous structures. Organic functionalization of porous materials provides a means of tuning the surface properties to control host/guest interactions and the hydrophobicity or hydrophilicity of the surface [31] as well as the mechanical and optical properties. Therefore, hierarchical porous materials (HPM), with interconnected pores of multiple length scales as the structure character, may be more active than other materials in the process of photocatalytic. Template-based processes demonstrate high efficiency for the construction of porous structures. Mesoporous products are always achieved by using the surfactant as soft template [32-35] or the obtained mesoporous materials as hard template [36].

In the present work, we reported the preparation and characterization of hierarchical porous $\alpha$-FeOOH nanoparticles via a facile polystyrene (PS) microspheres-templated method. These nanosized catalysts were characterized by the techniques such as XRD, SEM, TEM, and $\mathrm{N}_{2}$-sorption. The photocatalytic activities of the as-prepared catalysts were evaluated by the photocatalytic degradation of a model pollutant, RB under UV-light. The crystal structures, morphologies, and optical properties of resulting products were studied. The effect of calcination treatment temperature on the crystal structure and morphology of the final product was also investigated.

\section{Experimental Section}

2.1. Materials. Distilled water was used throughout this study. Iron nitrate nonahydrate $\left(\mathrm{Fe}\left(\mathrm{NO}_{3}\right)_{3} \cdot 9 \mathrm{H}_{2} \mathrm{O}\right)$, ethanol with absolute grade, tetrahydrofuran (THF), acetone, all chemicals used in this study were of analytical grade and were used as received without further purification. Iron nitrate nonahydrate $\left(\mathrm{Fe}\left(\mathrm{NO}_{3}\right)_{3} \cdot 9 \mathrm{H}_{2} \mathrm{O}\right)$ was purchased from Sinopharm Chemical Reagent Co., Ltd., and others were purchased from Tianjin Dengke Chemical Reagent Co., Ltd. Polystyrene (PS) microspheres were prepared by emulsion polymerization method. In a typical procedure, $150 \mathrm{~g}$ deionized water was poured into a $300 \mathrm{~mL}$ jacket reactor, which was kept at $85^{\circ} \mathrm{C}$ until the end of the reaction. Then, $0.075 \mathrm{~g}$ sodium styrene sulfonate and $0.0633 \mathrm{~g}$ sodium hydrogen carbonate were dissolved in the deionized water. Under constant stirring, $17.50 \mathrm{~mL}$ styrene monomer was added to this solution under the nitrogen protection. After $1 \mathrm{~h}, 0.0833 \mathrm{~g}$ potassium persulfate was introduced into the solution. After $18 \mathrm{~h}$ polymerization, the monodispersed PS spheres with the diameter of $247 \mathrm{~nm}$ were obtained.

2.2. Preparation of $\alpha-\mathrm{FeOOH}$ and $\alpha-\mathrm{Fe}_{2} \mathrm{O}_{3}$ Nanoparticles. The $\alpha-\mathrm{FeOOH}$ catalyst was prepared by a facile hydrolysis process of $\mathrm{Fe}\left(\mathrm{NO}_{3}\right)_{3} \cdot 9 \mathrm{H}_{2} \mathrm{O}$ aqueous solution using the polystyrene spheres as the template. In a typical procedure, $12.12 \mathrm{~g} \mathrm{Fe}\left(\mathrm{NO}_{3}\right)_{3} \cdot 9 \mathrm{H}_{2} \mathrm{O}$ was dissolved in a mixed solution of $20 \mathrm{~mL}$ ethanol and $10 \mathrm{~mL}$ distalled water under ultrasound irradiation for $10 \mathrm{~min}$; then $3.56 \mathrm{~g}$ PS microspheres was added in the prepared solution under vigorous stirring. After stirring for $30 \mathrm{~min}$, the resulting suspension was transferred into a $150 \mathrm{~mL}$ conical flask on the constant temperature magnetic heating stirrer (85-2), heated to $60^{\circ} \mathrm{C}$, and kept at the target temperature until a large tawny precipitate appeared. Then, the precipitate was dried at room temperature. The obtained sample was placed in glass soxhlet extractor and PS microspheres were extracted by the mixed solution of THF/acetone (1/1 of v/v) [31] for four days. Finally, the tawny precipitate was dried at $60^{\circ} \mathrm{C}$ in an oven and the tawny $\alpha$ $\mathrm{FeOOH}$ nanoparticles were obtained. The prepared sample was calcinated by slowly increasing temperature from room temperature to $200^{\circ} \mathrm{C}\left(300^{\circ} \mathrm{C}\right)$ at a ramping rate of $1^{\circ} \mathrm{C} \cdot \mathrm{min}^{-1}$ and kept the target temperature for $3 \mathrm{~h}$. Subsequently, the reactor was cooled to room temperature naturally. The obtained red-brown samples were nominated as $\alpha-\mathrm{Fe}_{2} \mathrm{O}_{3}-200$ and $\alpha-\mathrm{Fe}_{2} \mathrm{O}_{3}-300$, respectively.

2.3. Analytical Methods. XRD analysis was performed on a Bruker-AXS D8 advance diffractometer, with $\mathrm{CuK} \alpha$ radiation at $40 \mathrm{KV}$ and $25 \mathrm{~mA}$ in a scanning range of $10-80^{\circ}(2 \theta)$. The diffraction peaks of the crystalline phase were compared with those of standard compounds reported in the JCPDS Date File. The texture and morphology of the prepared samples were measured by SEM (JEOL JSM-6390LV). TEM analysis was performed on a JEOL JEM-2100 microscope, operating at $200 \mathrm{kV}$. The sample was dispersed in ethanol, treated with ultrasound for $5 \mathrm{~min}$, and then deposited on a copper grid coated with preformed holey carbon film. $\mathrm{N}_{2}$ adsorption-desorption isotherms were collected at liquid 
nitrogen temperature using a Quantachrome NOVA 2000e sorption analyzer. The specific surface areas of the samples were calculated following the multipoint BET (BrunauerEmmett-Teller) procedure. The pore size distributions were determined from the adsorption branch of the isotherms using the DFT method. Before carrying out the measurement, each sample was degassed at $80^{\circ} \mathrm{C}$ for more than $6 \mathrm{~h}$.

2.4. Photocatalytic/Adsorption Activity. The photocatalytic activity experiments of the obtained catalysts were performed by the degradation of RB dye under UV light irradiation in the air at room temperature. $0.1 \mathrm{~g}$ of the obtained product was placed into water-jacketed reactor of $100 \mathrm{~mL}$ of $\mathrm{RB}$ aqueous solution $\left(2 \times 10^{-5} \mathrm{~mol} \cdot \mathrm{L}^{-1}\right)$. The light source was a $450 \mathrm{~W}$ high-pressure mercury lamp (Foshan Electrical and Lighting Co., Ltd.) and the lamp was located $10 \mathrm{~cm}$ higher than the solution surrounded by a circulating water tube. The reaction mixture was stirred under UV light irradiation. The mixture sampled at different times was centrifuged for $15 \mathrm{~min}$ to discard any sediment. The absorbance of reaction solutions was measured by a TU-1810 UV-Vis spectrophotometer at its characteristic wavelength $(\lambda=553 \mathrm{~nm})[37,38]$. The decomposition rate of Rhodamine $B$ was calculated by the following formula:

$$
\text { Decomposition rate }=\frac{A_{0}-A}{A_{0}} \times 100 \% \text {, }
$$

where $A_{0}$ is the absorbance of the RB solution before irradiation and $A$ is the absorbance of RB solution after irradiation.

The adsorption capacity of the catalysts was measured in the similar way to that of photocatalytic activity measurements. The only difference is that the adsorption process was carried out without UV irradiation.

\section{Results and Discussion}

\subsection{Characterization of Nanoparticles}

3.1.1. X-Ray Diffraction of $\alpha-\mathrm{FeOOH}$ and $\alpha-\mathrm{Fe}_{2} \mathrm{O}_{3}$ Samples. $\mathrm{X}$-ray diffraction (XRD) was used for identification of the crystalline phases of the crystallite size. Figure 1 shows the typical XRD patterns of the as-prepared samples. It can be seen clearly from Figure 1(a) that the reflection peaks of as-prepared sample can be perfectly attributed to the standard card of $\alpha-\mathrm{FeOOH}$ (JCPDS 29-713) phase. After the calcination of the $\alpha-\mathrm{FeOOH}$ precursor at $200^{\circ} \mathrm{C}$ and $300^{\circ} \mathrm{C}$ for $3 \mathrm{~h}$, respectively. All the diffraction peaks of the products (Figures 1(b) and 1(c)) can be well indexed to hexagonal $\alpha-\mathrm{Fe}_{2} \mathrm{O}_{3}$ (JCPDS 33-0664). No characteristic peaks of impurities were observed, indicating the thorough phase transformation from $\alpha$-FeOOH to $\alpha-\mathrm{Fe}_{2} \mathrm{O}_{3}$. The as-prepared $\alpha$-FeOOH sample (Figure 1(a)) had a weak crystallization, with the widest and weakest peaks. The enhanced peak sharpness in Figure 1(c) indicates the well crystallization of $\alpha-\mathrm{Fe}_{2} \mathrm{O}_{3}-300$ via the heat treatment.

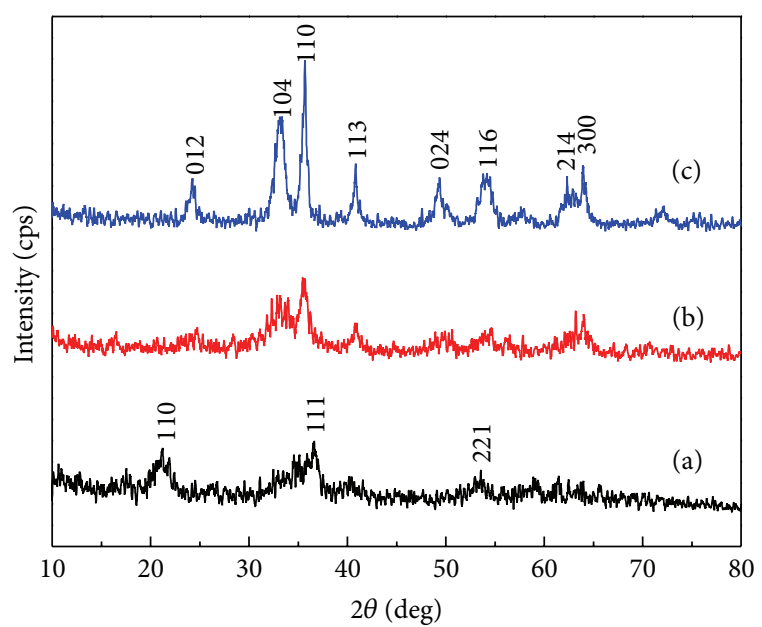

FIGURE 1: XRD patterns of (a) $\alpha-\mathrm{FeOOH}$, (b) $\alpha-\mathrm{Fe}_{2} \mathrm{O}_{3}-200$, and (c) $\alpha-\mathrm{Fe}_{2} \mathrm{O}_{3}-300$.

3.1.2. SEM Analysis of $\alpha-\mathrm{FeOOH}$ and $\alpha-\mathrm{Fe}_{2} \mathrm{O}_{3}-300$ Nanoparticles. Figures 2(a), 2(b), and 2(c) display the typical morphologies of the as-prepared $\alpha$-FeOOH and $\alpha-\mathrm{Fe}_{2} \mathrm{O}_{3}-300$ samples, respectively. The SEM images of Figures 2(a) and 2(b) show that the $\alpha$-FeOOH sample presented a threedimensional ordered arrangement of interconnected macropores with a mean pore diameter of about $230 \mathrm{~nm}$ (especially as shown in the selected area in Figure 2(a)), which was ca. 6-8\% smaller than the size of the original PS microspheres template, suggesting significant shrinkage during latex sphere extraction. The pores come from the removal of PS microspheres by extraction with THF/acetone mixture. From Figure 2(c) it can be seen that the result of $\alpha-\mathrm{Fe}_{2} \mathrm{O}_{3}$ product basically inherits the porous morphology of $\alpha$-FeOOH precursor, but most pore walls of the sample were collapsed. The result suggests that the calcination temperature has a negative influence on the macroporous structure. There are a few reports that the physical properties and photochemical performance are affected by the porous structure and the particle size $[22,27,30,39,40]$. Since the macroporous structure and large surface area of the samples convey high adsorption abilities of the catalysts. Therefore, we hypothesize that such changes may affect their adsorption properties and catalytic performance.

3.1.3. TEM Analysis of $\alpha-F e O O H$ Nanoparticles. TEM analysis is expected to provide further detailed insights into the pore structure of the as-prepared sample. Figure 3 displays the TEM images of the microstructure of the as-prepared $\alpha$ FeOOH nanoparticles. The results show that the walls are formed by the agglomeration of the nanoparticles, leading to significant textural mesoporosity within the walls of the structure. As seen in Figure 3(b), the sample consisted of a uniform structure with ordered macropore, which is in good agreement with the results provided by SEM (Figure 2(b)). Figure 3(c) shows that the wall thickness of $\alpha-\mathrm{FeOOH}$ is evaluated $8-13 \mathrm{~nm}$ and the nanoparticles of the sample are of regular size around $3 \mathrm{~nm}$. Hence, the electron microscopy 

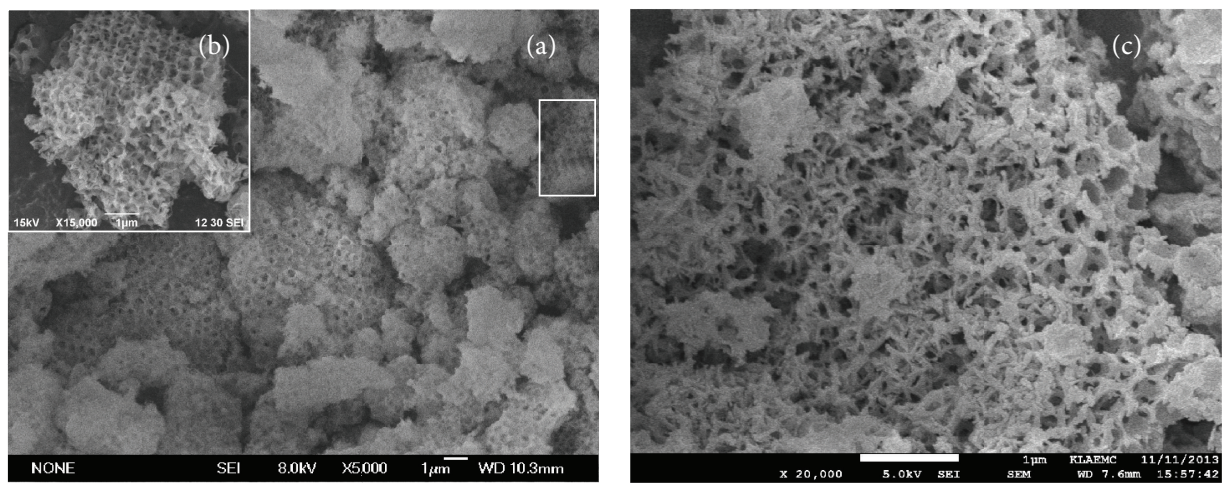

FIgURE 2: SEM images of $\alpha$-FeOOH and $\alpha-\mathrm{Fe}_{2} \mathrm{O}_{3}-300$ nanoparticles.
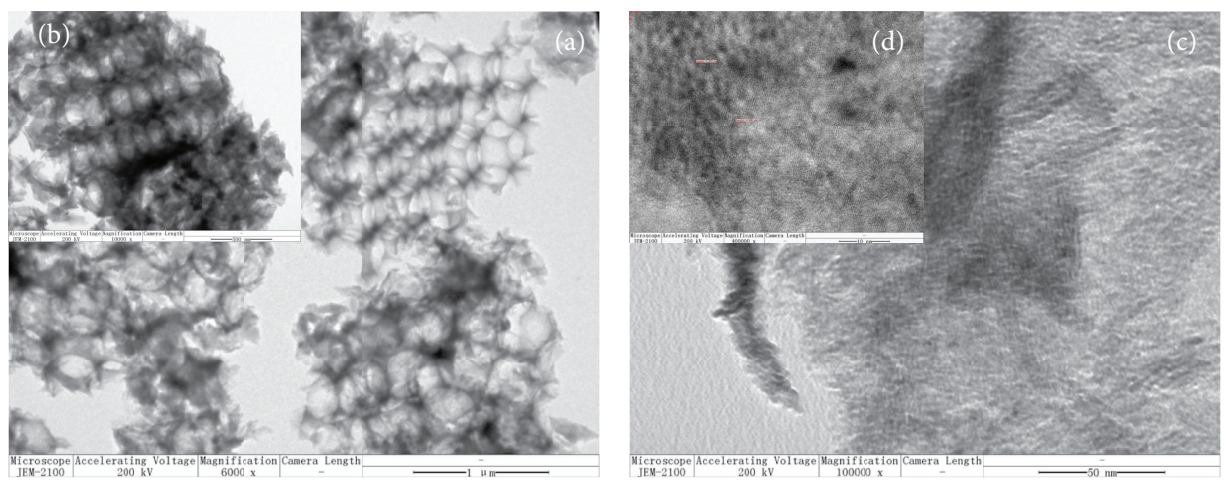

FIgURE 3: TEM images of $\alpha$-FeOOH nanoparticles.

observation results demonstrate that the products possess hierarchical porous structure.

3.1.4. $\mathrm{N}_{2}$-Sorption Analysis. Figure 4 depicts nitrogen adsorption-desorption isotherms and the corresponding pore size distributions of $\alpha-\mathrm{FeOOH}$ and $\alpha-\mathrm{Fe}_{2} \mathrm{O}_{3}-300$ samples. The textural properties of the samples are listed in Table 1. From Figure 4, we can see that the isotherms of the both of samples display type IV, characteristic of mesoporous materials according to the IUPAC. The adsorption isotherm of as-prepared samples exhibits a large increase at the $P / P_{0}$ above 0.8 , indicating the presence of the hierarchical macroporous structure. The porous structure is believed to facilitate the transporting of reactant molecules and products through the interior space due to the interconnected porous networks and favor the harvesting of exciting light due to enlarged surface area and multiple scattering within the porous framework [41].

The adsorption isotherms of the prepared catalysts exhibit a large increase in the $P / P_{0}$ range of $0.2-0.4$, which is characteristic of capillary condensation within mesopore. The pore size distribution curves of the $\alpha-\mathrm{FeOOH}$ as estimated according to the DFT method from the adsorption branch of the isotherm exhibit one single narrow peak centered at 1.6-2.7 nm (Figure 4(b)), indicating the good homogeneity of the pores. It can be seen that the diameter range of pores located form 1.68 to $18 \mathrm{~nm}$ and the mean diameter of pores is $4.7 \mathrm{~nm}$. This is attributed to the mesopore-sized void space between the crystallites, which are also observed in the TEM images. After calcination at $300^{\circ} \mathrm{C}$ for $3 \mathrm{~h}$, the surface area of the catalyst decrease from 217 to $151 \mathrm{~m}^{2} \cdot \mathrm{g}^{-1}$ (Table 1 ), accompanied with the increase of the pore volume and pore size. This may due to the collapse of the porous structure during the process of calcination. In general, the surface area varies before and after the calcination (Table 1), indicating that the characteristic structure of $\alpha-\mathrm{FeOOH}$ was destroyed, which is well agreement with the SEM results. This illustrates that the calcination treatment has negative impact on the textural properties of the prepared catalysts. The high surface area of the $\alpha$-FeOOH sample can be useful in the efficiency of the photocatalytic activity as it implies larger contact surfaces exposed to the reagents.

3.2. Photocatalytic/Adsorption Properties Studies. The photocatalytic activities of a series of catalysts were characterized by the degradation test of RB with UV irradiation (Figure 5 and Table 2). Figure 5(a) gives the evolution of RB absorption spectra in the presence of $0.1 \mathrm{~g}$ of the photocatalyst per $100 \mathrm{~mL}$ of RB solution after irradiated under UV light for different times. From the top plot in Figure 5(a), it can be seen that the RB solution exhibits an obvious absorption peaks at $553 \mathrm{~nm}$. The absorption intensity of RB solution gradually decreases with prolonged irradiation time, indicating the effective photodegradation of $\mathrm{RB}$ under the catalysis of porous $\alpha$-FeOOH 


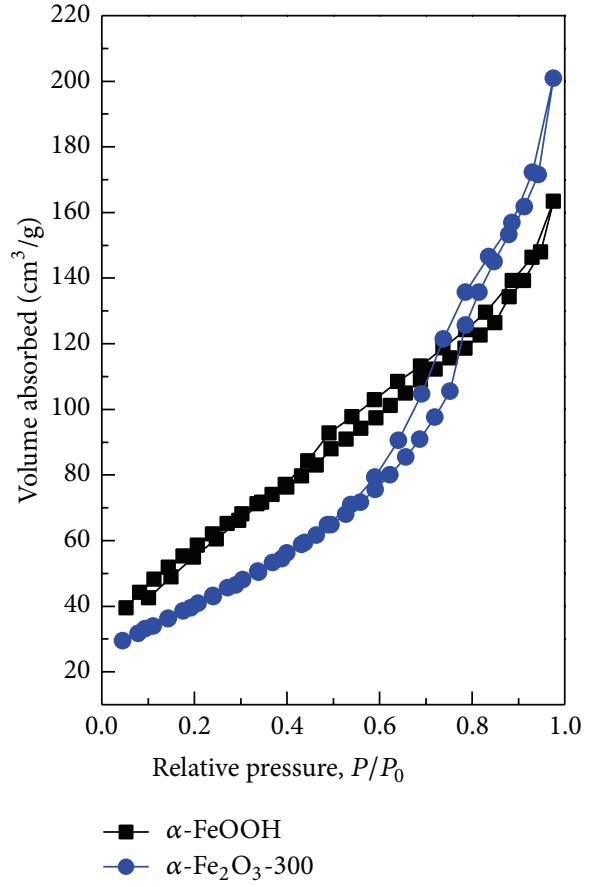

(a)

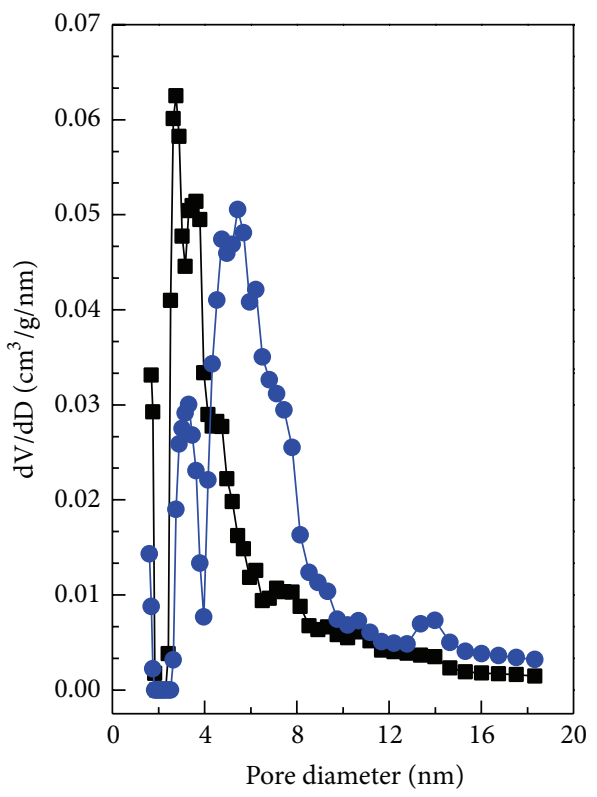

(b)

FIGURE 4: (a) $\mathrm{N}_{2}$ adsorption-desorption isotherms and (b) the corresponding pore size distribution curves of $\alpha-\mathrm{FeOOH}$ and $\alpha-\mathrm{Fe}_{2} \mathrm{O}_{3}$ 300.

nanoparticles. As can be seen, with increasing irradiation time for $\alpha$-FeOOH sample, the major absorbance of $\mathrm{RB}$ in the UV regions decreased and the positions of major absorbance were slightly shifted to low wavenumber, suggesting that both chromphore and aromatic rings of RB were destroyed, instead of being simply decolorized by adsorption process [42].

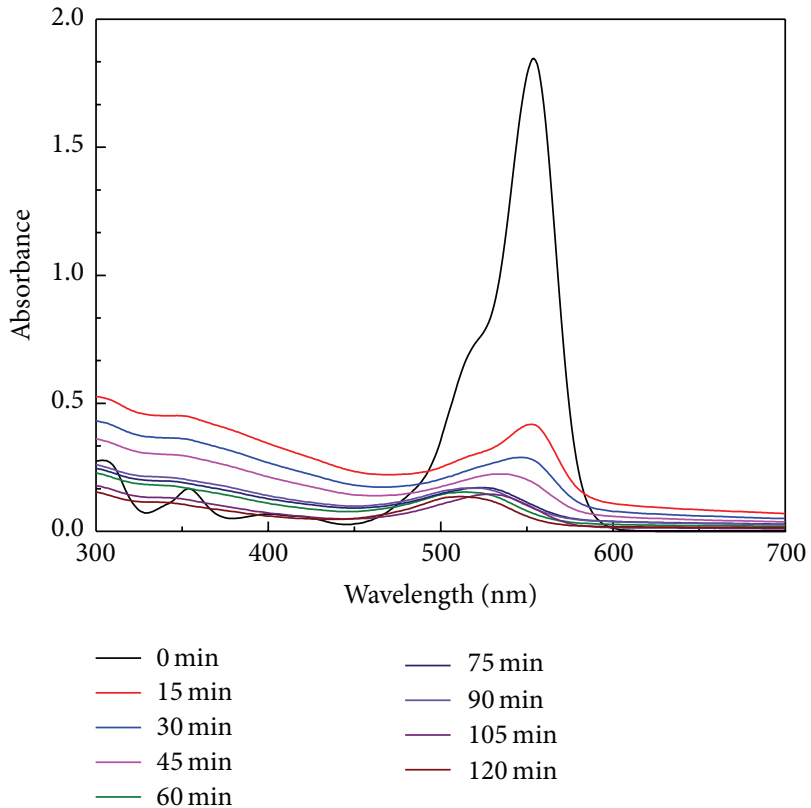

(a)

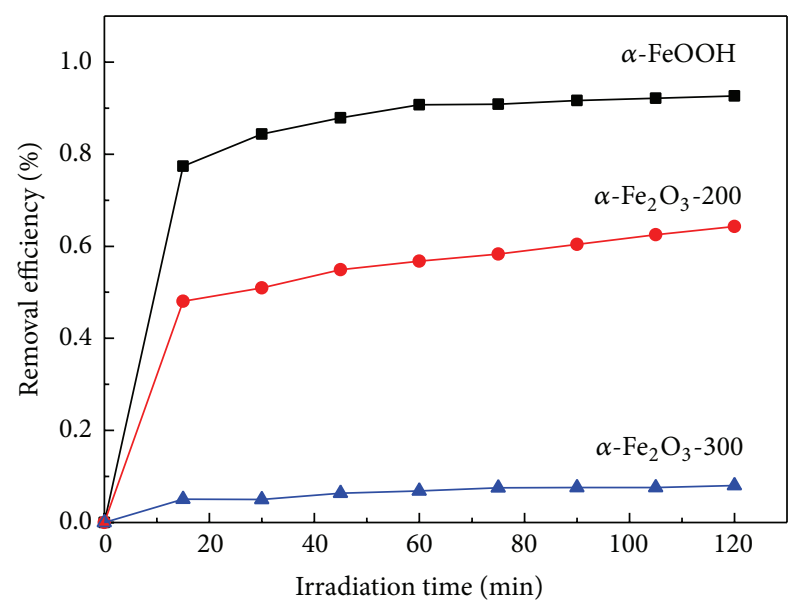

(b)

FIgURE 5: (a) Temporal evolution of RB absorption spectra with an initial concentration $C_{0}$ of $2 \times 10^{-5} \mathrm{~mol} \cdot \mathrm{L}^{-1}$ under UV light with porous $\alpha$-FeOOH nanoparticles as photocatalyst; (b) removal efficiency of RB after photodecomposition by the different catalysts under UV light.

Figure 5(b) shows that the removal efficiency of RB after photodecomposition by the different catalysts under UV light. It can be clearly seen that the order of photocatalytic activity for the degradation of RB was as follows: $\alpha-\mathrm{FeOOH}>$ $\alpha-\mathrm{Fe}_{2} \mathrm{O}_{3}-200>\alpha-\mathrm{Fe}_{2} \mathrm{O}_{3}-300$. After the irradiation of $2 \mathrm{~h}$, the degradation percentage of the $\mathrm{RB}$ reaches $92.6 \%$ with $\alpha-\mathrm{FeOOH}$ as catalyst, while it is only $64.3 \%$ and $8 \%$ with $\alpha-\mathrm{Fe}_{2} \mathrm{O}_{3}-200$ and $\alpha-\mathrm{Fe}_{2} \mathrm{O}_{3}-300$ as catalyst, respectively. This may be caused by the higher adsorptive ability of $\alpha$-FeOOH (see Table 2). It is generally accepted that the catalytic process is mainly related to the adsorption and desorption of organic molecules on the surface of photocatalyst. Since the decrease 
TABLE 1: The textural properties of the as-prepared catalysts.

\begin{tabular}{lcccc}
\hline Sample & Surface $\mathrm{area}^{\mathrm{a}}\left(\mathrm{m}^{2} \cdot \mathrm{g}^{-1}\right)$ & Pore volume $^{\mathrm{b}}\left(\mathrm{cm}^{3} \cdot \mathrm{g}^{-1}\right)$ & $\mathrm{D}_{\text {DFT-ads }}{ }^{\mathrm{c}}(\mathrm{nm})$ & Mean pore diameter \\
\hline$\alpha-\mathrm{FeOOH}$ & 217.02 & 0.253 & 2.77 & 4.7 \\
$\alpha-\mathrm{Fe}_{2} \mathrm{O}_{3}-300$ & 151.63 & 0.311 & 3.32 & 41.0 \\
\hline
\end{tabular}

${ }^{\mathrm{a}}$ Multipoint BET surface area.

${ }^{\mathrm{b}}$ Total pore volume at $P / P_{0}=0.97$.

${ }^{\mathrm{c}}$ Maximum of DFT pore diameter as determined from the adsorption branch.

${ }^{\mathrm{d}}$ Average pore diameter (4V/A).

TABLE 2: Absorption and photodegradation rate of RB by different catalysts within $2 \mathrm{~h}$.

\begin{tabular}{lccc}
\hline Sample & $\alpha$-FeOOH & $\alpha-\mathrm{Fe}_{2} \mathrm{O}_{3}-200$ & $\alpha-\mathrm{Fe}_{2} \mathrm{O}_{3}-300$ \\
\hline Absorption (\%) & 66.6 & 45.0 & 5.1 \\
Removal rate of RB (\%) & 92.6 & 64.3 & 8.0 \\
\hline
\end{tabular}

of the absorption intensity might also be caused by adsorption rather than photocatalytic degradation, we carried out the control experiments under dark in the presence of $\alpha$ FeOOH for $2 \mathrm{~h}$. Generally, the higher absorption capacity is, the better the photocatalytic activity of the prepared catalyst would be (see Table 2 and Figure 5(b)). The control experiments further confirm the highly adsorption performance and a certain degradation activity of the $\alpha$-FeOOH nanoparticles.

The high surface area of the $\alpha-\mathrm{FeOOH}$ sample can provide more unsaturated surface sites exposed to the reactants and the mesopores in the catalyst enable storage of more reactant molecules. The UV absorption measurement suggests that the high adsorption performance and a certain photocatalytic efficiency of the $\alpha$-FeOOH nanoparticles are closely related to its structure. Thus, the high specific surface area, hierarchical porous structure, and finer absorptive ability are responsible for achieving better photodegradation performance.

\section{Conclusions}

In summary, hierarchical porous $\alpha$-FeOOH network structures were successfully constructed using a facile polystyrene (PS) microspheres-templated method. The photocatalytic performances of the as-prepared samples were evaluated in the degradation of RB solution under UV light irradiation. And, the photocatalytic activities exhibit an order of $\alpha$ $\mathrm{FeOOH}>\alpha-\mathrm{Fe}_{2} \mathrm{O}_{3}-200>\alpha-\mathrm{Fe}_{2} \mathrm{O}_{3}-300$. The observed high photocatalytic activity is related to the structural features of hierarchically multiporous structure, high surface area, and uniform distribution of $\alpha$-FeOOH particles with nanoscale size. Considering the superior photocatalytic activity, good absorption property, and facile preparation method, the porous $\alpha$-FeOOH nanoparticles are believed to have potential application in the field of photodegradation of dye in the waste water.

\section{Conflict of Interests}

The authors have no conflict of interests in relation with the instrumental companies directly or indirectly.

\section{Acknowledgments}

This work was supported by the National Natural Science Foundation of China (51172065, U1304520), China Postdoctoral Science Foundation Funded Project (2012M521394), Specialized Research Fund for the Doctoral Program of Higher Education (20124116120002), State Key Laboratory Cultivation Base for Gas Geology and Gas Control (WS2013B03), Program for Innovative Research Team in the University of Henan Province (2012IRTSTHN007), the Education Department Natural Science Foundation of He'nan Province (2011B150009, 13A430315), and the Opening Project of Henan Key Discipline Open Laboratory of Mining Engineering Materials (MEM13-1).

\section{References}

[1] B. Li, Y. Dong, Z. Ding, Y. Xu, and C. Zou, "Renovation and reuse of reactive dyeing effluent by a novel heterogeneous Fenton system based on metal modified PTFE fibrous catalyst/ $\mathrm{H}_{2} \mathrm{O}_{2}$," International Journal of Photoenergy, vol. 2013, Article ID 169493, 10 pages, 2013.

[2] S. Yi, Y. Dong, B. Li, Z. Ding, X. Huang, and L. Xue, "Adsorption and fixation behaviour of CI Reactive Red 195 on cotton woven fabric in a nonionic surfactant Triton X-100 reverse micelle," Coloration Technology, vol. 128, no. 4, pp. 306-314, 2012.

[3] P.-H. Chou, S. Matsui, K. Misaki, and T. Matsuda, "Isolation and identification of xenobiotic aryl hydrocarbon receptor ligands in dyeing wastewater," Environmental Science \& Technology, vol. 41, no. 2, pp. 652-657, 2007.

[4] A. Khalid, M. Arshad, and D. E. Crowley, "Biodegradation potential of pure and mixed bacterial cultures for removal of 4nitroaniline from textile dye wastewater," Water Research, vol. 43, no. 4, pp. 1110-1116, 2009.

[5] W. Chen, W. Lu, Y. Yao, and M. Xu, "Highly efficient decomposition of organic dyes by aqueous-fiber phase transfer and in situ catalytic oxidation using fiber-supported cobalt phthalocyanine," Environmental Science \& Technology, vol. 41, no. 17, pp. 6240-6245, 2007.

[6] Z. Chen, D. Li, W. Zhang et al., "Photocatalytic degradation of dyes by $\mathrm{ZnIn}_{2} \mathrm{~S}_{4}$ microspheres under visible light irradiation," The Journal of Physical Chemistry C, vol. 113, no. 11, pp. 44334440, 2009. 
[7] S. D. Richardson, C. S. Willson, and K. A. Rusch, "Use of rhodamine water tracer in the marshland upwelling system," Groundwater, vol. 42, no. 5, pp. 678-688, 2004.

[8] D. Kornbrust and T. Barfknecht, "Testing of 24 food, drug, cosmetic, and fabric dyes in the in vitro and the in vivo/in vitro rat hepatocyte primary culture/DNA repair assays," Environmental Mutagenesis, vol. 7, no. 1, pp. 101-120, 1985.

[9] M. Constapel, M. Schellenträger, J. M. Marzinkowski, and S. Gäb, "Degradation of reactive dyes in wastewater from the textile industry by ozone: analysis of the products by accurate masses," Water Research, vol. 43, no. 3, pp. 733-743, 2009.

[10] S. Eftekhari, A. Habibi-Yangjeh, and Sh. Sohrabnezhad, "Application of AlMCM-41 for competitive adsorption of methylene blue and rhodamine B: thermodynamic and kinetic studies," Journal of Hazardous Materials, vol. 178, no. 1-3, pp. 349-355, 2010.

[11] A. B. dos Santos, F. J. Cervantes, and J. B. van Lier, "Review paper on current technologies for decolourisation of textile wastewaters: perspectives for anaerobic biotechnology," Bioresource Technology, vol. 98, no. 12, pp. 2369-2385, 2007.

[12] J. M. Monteagudo, A. Durán, and C. López-Almodóvar, "Homogeneus ferrioxalate-assisted solar photo-Fenton degradation of orange II aqueous solutions," Applied Catalysis B, vol. 83, no. 1-2, pp. 46-55, 2008.

[13] O. Zahraa, S. Maire, F. Evenou et al., "Treatment of wastewater dyeing agent by photocatalytic process in solar reactor," International Journal of Photoenergy, vol. 2006, Article ID 46961, 9 pages, 2006.

[14] O. Sacco, M. Stoller, V. Vaiano, P. Ciambelli, A. Chianese, and D. Sannino, "Photocatalytic degradation of organic dyes under visible light on $\mathrm{N}$-doped $\mathrm{TiO}_{2}$ photocatalysts," International Journal of Photoenergy, vol. 2012, Article ID 626759, 8 pages, 2012.

[15] A. Afkhami and R. Moosavi, "Adsorptive removal of Congo red, a carcinogenic textile dye, from aqueous solutions by maghemite nanoparticles," Journal of Hazardous Materials, vol. 174, no. 1-3, pp. 398-403, 2010.

[16] M.-C. Chang, H.-Y. Shu, T.-H. Tseng, and H.-W. Hsu, "Supported zinc oxide photocatalysts for decolorization and mineralization of orange G dye wastewater under UV365 irradiation," International Journal of Photoenergy, vol. 2013, Article ID 595031, 12 pages, 2013.

[17] T.-K. Jia, W.-M. Wang, F. Long, Z.-Y. Fu, H. Wang, and Q.-J. Zhang, "Fabrication, characterization and photocatalytic activity of La-doped $\mathrm{ZnO}$ nanowires," Journal of Alloys and Compounds, vol. 484, no. 1-2, pp. 410-415, 2009.

[18] T.-K. Jia, W.-M. Wang, F. Long, Z.-Y. Fu, H. Wang, and Q.-J. Zhang, "Synthesis, characterization, and photocatalytic activity of $\mathrm{Zn}$-doped $\mathrm{SnO}_{2}$ hierarchical architectures assembled by nanocones," The Journal of Physical Chemistry C, vol. 113, no. 21, pp. 9071-9077, 2009.

[19] X. Chen and S. S. Mao, “Titanium dioxide nanomaterials: synthesis, properties, modifications and applications," Chemical Reviews, vol. 107, no. 7, pp. 2891-2959, 2007.

[20] M. F. Hochella Jr., S. K. Lower, P. A. Maurice et al., "Nanominerals, mineral nanoparticles, and earth systems," Science, vol. 319, no. 5870, pp. 1631-1635, 2008.

[21] A. Navrotsky, L. Mazeina, and J. Majzlan, "Size-driven structural and thermodynamic complexity in iron oxides," Science, vol. 319, no. 5870, pp. 1635-1638, 2008.
[22] X. Zhou, H. Yang, C. Wang et al., "Visible light induced photocatalytic degradation of rhodamine B on one-dimensional iron oxide particles," The Journal of Physical Chemistry C, vol. 114, no. 40, pp. 17051-17061, 2010.

[23] E. Esmaeili, M. Salavati-Niasari, F. Mohandes, F. Davar, and H. Seyghalkar, "Modified single-phase hematite nanoparticles via a facile approach for large-scale synthesis," Chemical Engineering Journal, vol. 170, no. 1, pp. 278-285, 2011.

[24] L.-P. Zhu, H.-M. Xiao, X.-M. Liu, and S.-Y. Fu, “Template-free synthesis and characterization of novel 3D urchin-like $\alpha-\mathrm{Fe}_{2} \mathrm{O}_{3}$ superstructures," Journal of Materials Chemistry, vol. 16, no. 19, pp. 1794-1797, 2006.

[25] U. Cvelbar, Z. Chen, M. K. Sunkara, and M. Mozetič, "Spontaneous growth of superstructure $\alpha-\mathrm{Fe}_{2} \mathrm{O}_{3}$ nanowire and nanobelt arrays in reactive oxygen plasma," Small, vol. 4, no. 10, pp. 1610-1614, 2008.

[26] J. Chen, L. Xu, W. Li, and X. Gou, " $\alpha-\mathrm{Fe}_{2} \mathrm{O}_{3}$ nanotubes in gas sensor and lithium-ion battery applications," Advanced Materials, vol. 17, no. 5, pp. 582-586, 2005.

[27] C. Wu, P. Yin, X. Zhu, C. OuYang, and Y. Xie, "Synthesis of hematite $\left(\alpha-\mathrm{Fe}_{2} \mathrm{O}_{3}\right)$ nanorods: diameter-size and shape effects on their applications in magnetism, lithium ion battery, and gas sensors," The Journal of Physical Chemistry B, vol. 110, no. 36, pp. 17806-17812, 2006.

[28] F. Dong, A. Zheng, Y. Sun et al., "One-pot template-free synthesis, growth mechanism and enhanced photocatalytic activity of monodisperse $(\mathrm{BiO})_{2} \mathrm{CO}_{3}$ hierarchical hollow microspheres self-assembled with single-crystalline nanosheets," CrystEngComm, vol. 14, no. 10, pp. 3534-3544, 2012.

[29] A. S. Madden and M. F. Hochella Jr., "A test of geochemical reactivity as a function of mineral size: manganese oxidation promoted by hematite nanoparticles," Geochimica et Cosmochimica Acta, vol. 69, no. 2, pp. 389-398, 2005.

[30] S. Zeng, K. Tang, T. Li et al., "Facile route for the fabrication of porous hematite nanoflowers: its synthesis, growth mechanism, application in the lithium ion battery, and magnetic and photocatalytic properties," The Journal of Physical Chemistry C, vol. 112, no. 13, pp. 4836-4843, 2008.

[31] R. C. Schroden, M. Al-Daous, S. Sokolov et al., "Hybrid macroporous materials for heavy metal ion adsorption," Journal of Materials Chemistry, vol. 12, no. 11, pp. 3261-3267, 2002.

[32] J. Lee, M. C. Orilall, S. C. Warren, M. Kamperman, F. J. Disalvo, and U. Wiesner, "Direct access to thermally stable and highly crystalline mesoporous transition-metal oxides with uniform pores," Nature Materials, vol. 7, no. 3, pp. 222-228, 2008.

[33] L.-L. Li, J. Xu, Q. Yuan, Z.-X. Li, W.-G. Song, and C.-H. Yan, "Facile synthesis of macrocellular mesoporous foamlike $\mathrm{Ce}-$ Sn mixed oxides with a nanocrystalline framework by using triblock copolymer as the single template," Small, vol. 5, no. 23, pp. 2730-2737, 2009.

[34] Q. Yuan, H.-H. Duan, L.-L. Li et al., "Homogeneously dispersed ceria nanocatalyst stabilized with ordered mesoporous alumina," Advanced Materials, vol. 22, no. 13, pp. 1475-1478, 2010.

[35] D. Niu, Z. Ma, Y. Li, and J. Shi, "Synthesis of core-shell structured dual-mesoporous silica spheres with tunable pore size and controllable shell thickness," Journal of the American Chemical Society, vol. 132, no. 43, pp. 15144-15147, 2010.

[36] K. Brezesinski, J. Haetge, J. Wang et al., "Ordered mesoporous $\alpha-\mathrm{Fe}_{2} \mathrm{O}_{3}$ (hematite) thin-film electrodes for application in high rate rechargeable lithium batteries," Small, vol. 7, no. 3, pp. 407414, 2011. 
[37] E. T. Soares, M. A. Lansarin, and C. C. Moro, "A study of process variables for the photocatalytic degradation of rhodamine B," Brazilian Journal of Chemical Engineering, vol. 24, no. 1, pp. 2936, 2007.

[38] K. Byrappa, A. K. Subramani, S. Ananda, K. M. Lokanatha Rai, R. Dinesh, and M. Yoshimura, "Photocatalytic degradation of rhodamine B dye using hydrothermally synthesized $\mathrm{ZnO}$," Bulletin of Materials Science, vol. 29, no. 5, pp. 433-438, 2006.

[39] L. Song and S. Zhang, "Formation of $\alpha-\mathrm{Fe}_{2} \mathrm{O}_{3} / \mathrm{FeOOH}$ nanostructures with various morphologies by a hydrothermal route and their photocatalytic properties," Colloids and Surfaces A, vol. 348, no. 1-3, pp. 217-220, 2009.

[40] N. Smirnova, Y. Gnatyuk, A. Eremenko et al., "Photoelectrochemical characterization and photocatalytic properties of mesoporous $\mathrm{TiO}_{2} / \mathrm{ZrO}_{2}$ films," International Journal of Photoenergy, vol. 2006, Article ID 85469, 6 pages, 2006.

[41] P. Madhusudan, J. Ran, J. Zhang, J. Yu, and G. Liu, "Novel urea assisted hydrothermal synthesis of hierarchical $\mathrm{BiVO}_{4} /$ $\mathrm{Bi}_{2} \mathrm{O}_{2} \mathrm{CO}_{3}$ nanocomposites with enhanced visible-light photocatalytic activity," Applied Catalysis B, vol. 110, pp. 286-295, 2011.

[42] M. Hojamberdiev, G. Zhu, A. Eminov, and K. Okada, "Template-free hydrothermal synthesis of hollow $\alpha$-FeOOH urchinlike spheres and their conversion to $\alpha-\mathrm{Fe}_{2} \mathrm{O}_{3}$ under lowtemperature thermal treatment in air," Journal of Cluster Science, vol. 24, no. 1, pp. 97-106, 2013. 

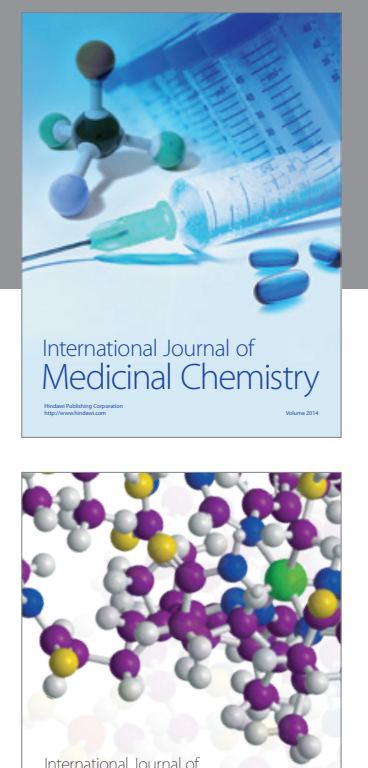

\section{Carbohydrate} Chemistry

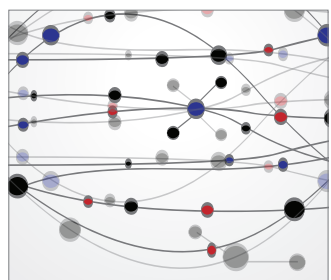

The Scientific World Journal
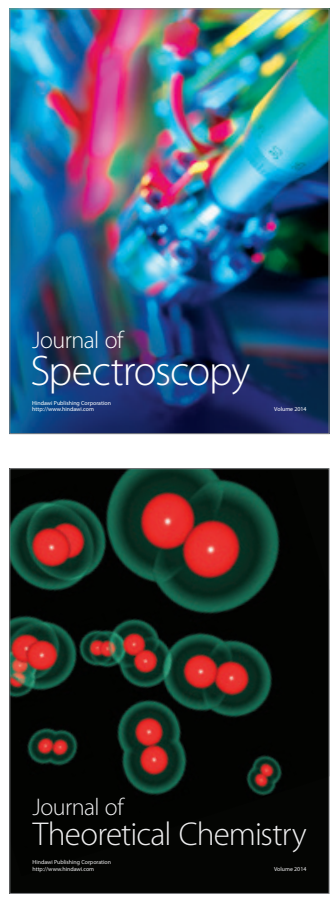
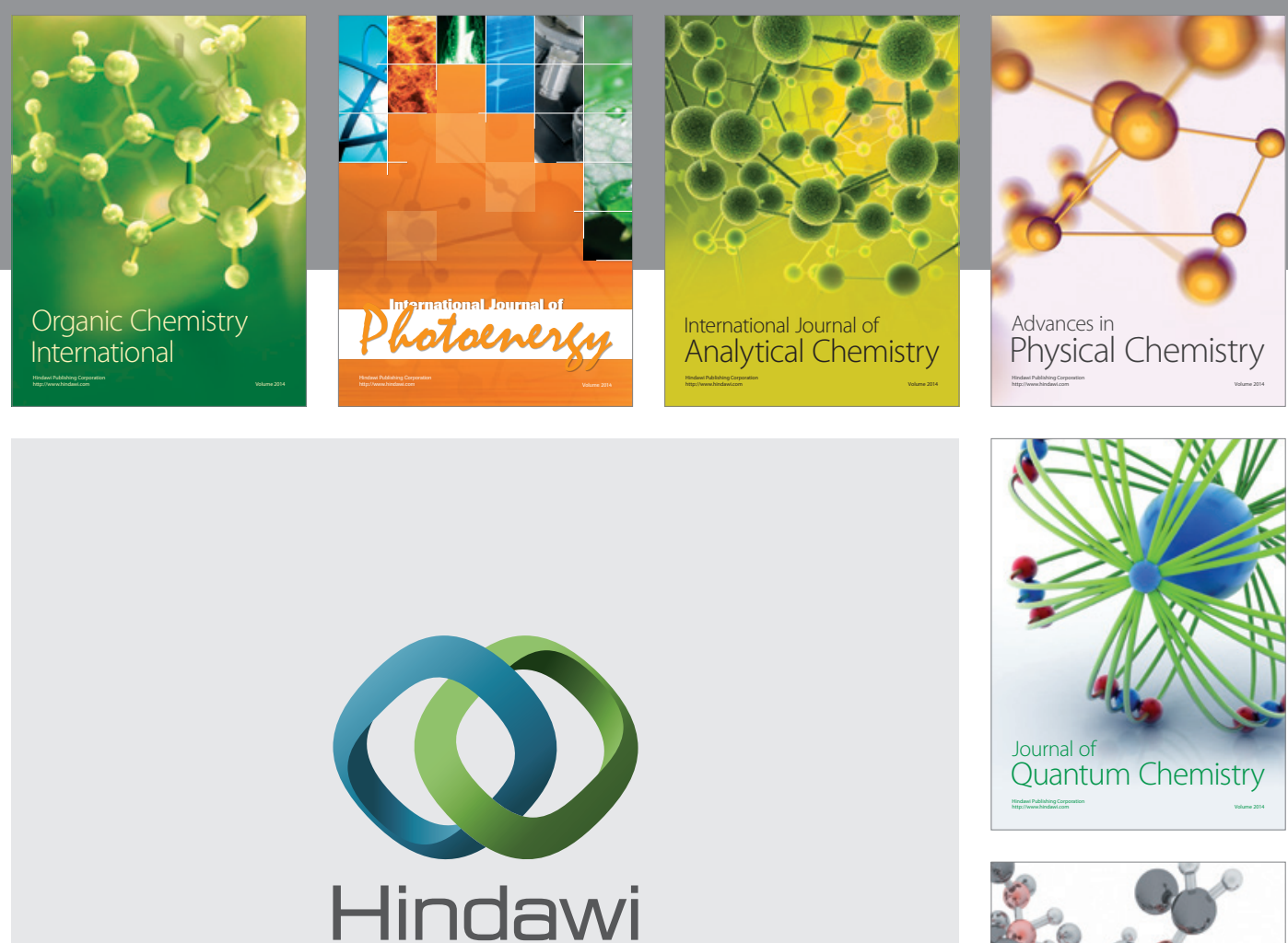

Submit your manuscripts at

http://www.hindawi.com

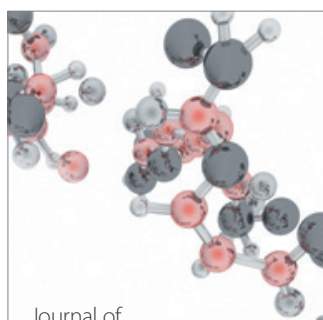

Analytical Methods

in Chemistry

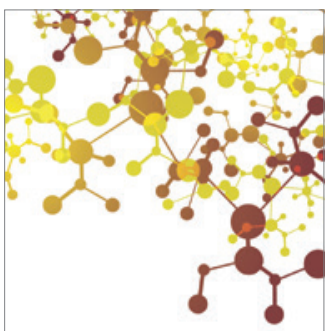

Journal of

Applied Chemistry

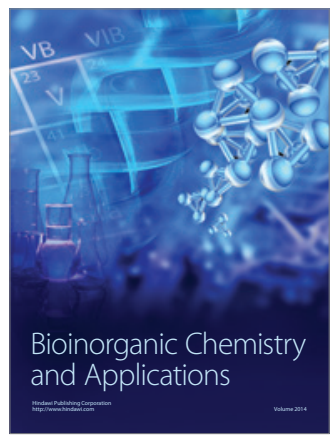

Inorganic Chemistry
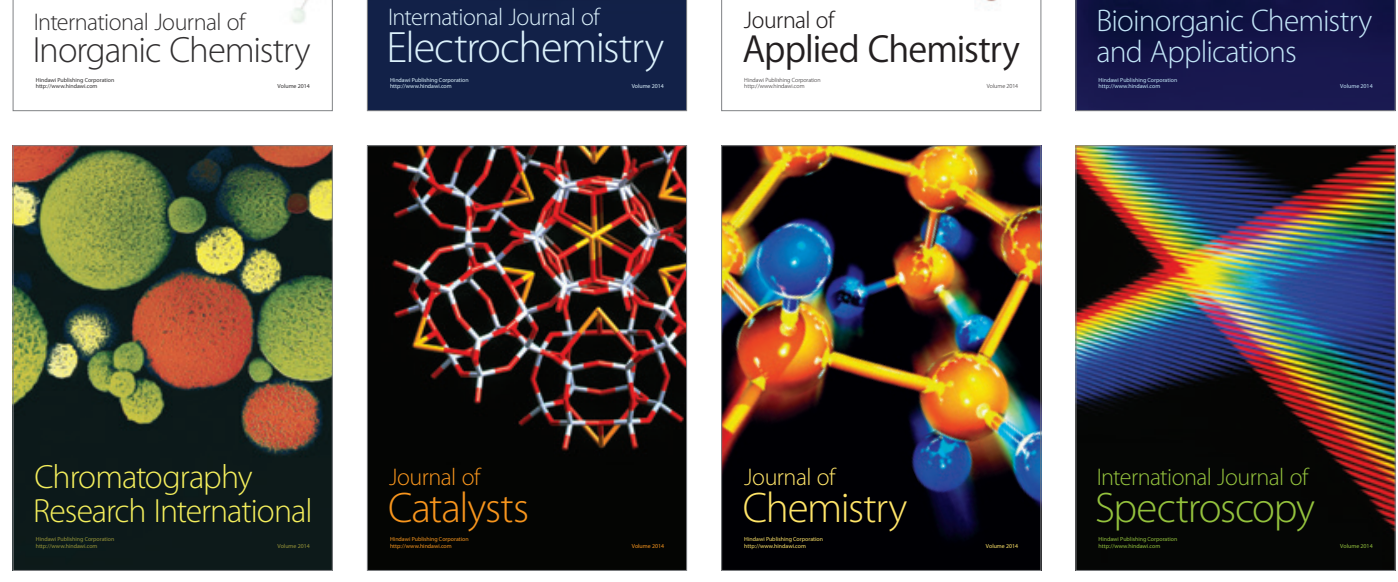